\section{Aquaculture}

Vol. 255, Issues 1-4, 31 May 2006, Pages 522-531

http://dx.doi.org/10.1016/i.aquaculture.2006.01.009

(C) 2006 Elsevier B.V. All rights reserved.
Archimer, archive institutionnelle de l'Ifremer http://www.ifremer.fr/docelec/

\title{
Human chorionic gonadotropin induces spermatogenesis and spermiation in 1-year-old European sea bass (Dicentrarchus labrax): Assessment of sperm quality
}

\author{
Roberta Schiavone ${ }^{\underline{a}}{ }^{\text {, }}$, Loredana Zilli ${ }^{\underline{a}}$, Sebastiano Vilella ${ }^{\underline{\underline{a}}}$ and Christian Fauvel ${ }^{\underline{\underline{b}}}$
}

\begin{abstract}
a Laboratory of Comparative Physiology, Department of Biological and Environmental Sciences and Technologies, University of Lecce, Via Provinciale Lecce-Monteroni, 73100 Lecce, Italy

b Station Expérimentale D'Aquaculture, IFREMER, Chemin de Maguelone, 34250 Palavas, France
\end{abstract}

*: Corresponding author : roberta.schiavone@unile.it

\begin{abstract}
The aims of the present study were (a) to compare sperm quality (percentage of motile spermatozoa, motility duration, density and fertility after cryopreservation) between precocious and normally maturing male European sea bass Dicentrarchus labrax, (b) to examine the potential of human chorionic gonadotropin (hCG) to increase spermiation in precocious males and (c) to examine the potential of hCG to induce spermatogenesis and spermiation in non-precocious 1-year-old males. One hundred precocious and 100 non-precocious fish were each randomly divided in two groups each: control (precocious saline-treated and non precocious saline-treated) and treated (precocious hCG-treated and non precocious hCG-treated). Treated groups were administered weekly with 1000 IU hCG kg ${ }^{-1}$ body weight while control groups were injected with physiological solution. Milt volume produced, sperm concentration, motility duration and fertilising ability were assessed every week in each group. The effect of the hormonal treatment on gonadal development was examined based on the gonadosomatic index and testicular histology. The results demonstrate that sperm produced by precocious fish has characteristics (mean value of motility class, mean maximum motility duration, concentration and fertility after cryopreservation) similar $(P>0.05)$ to those produced by 2 -year-old fish. Human chorionic gonadotropin treatment in precocious fish resulted in a significant increase $(P<0.05)$ of milt volume, without affecting sperm quality. In non-precocious fish, hCG treatment resulted in greater percentage of spermiation $(P<0.05)$ compared to non-precocious saline-treated group. At the end of the trial (three weeks), 29 out of 50 non-precocious hCG-treated fish were spermiating and, within these 23 produced $>200 \mu \mathrm{l}$ per fish of milt. No differences were observed in terms of sperm concentration, motility class, motility duration and fertilizing capacity due to hCG treatment in either precocious, or non-precocious fish. In addition, analysis of the testicular histology of fish that did not spermiate after hCG treatment, shows a significant $(P<0.05)$ enhancement of testicular development stages. The present study demonstrated that (a) precocious European sea bass males produce milt of comparable sperm characteristics to adult individuals, (b) treatment of nonprecocious males with hCG induced spermatogenesis and spermiation and (c) treatment of precocious males with hCG enhanced milt volume without affecting other sperm characteristics, including fertilizing ability.
\end{abstract}

Keywords: Spermatogenesis; Spermiation; European sea bass; hCG; Dicentrarchus labrax 
63

64

65

66

67

\section{Introduction}

The European sea bass Dicentrarchus labrax (L.) is an important commercial species and has been the subject of both basic and applied research. Studies have been carried out on its biology, control of reproduction, gamete quality, broodstock management and offspring quality (Carrillo et al., 1993; Pickett and Pawson, 1994; Carrillo et al., 1995). Under optimal conditions, European sea bass reproduce spontaneously in captivity. Females attain sexual maturity at 3 years of age and males at 2 years of age, but under culture conditions a large number of precocious males are observed (Carrillo et al., 1995; Asturiano et al., 2000).

The age at which fish reach sexual maturity is important for aquaculture, since in some species maturing individuals exhibit reduced somatic growth, as they divert energy from muscle growth into gonadal development (Bye and Lincoln, 1986). In these cases, sexual maturation is generally undesirable in fish production. On the other hand, fish breeders may benefit from using early maturing broodstock, to reduce generation interval, allowing faster selection of genetic characters of interest. From this point of view, the development of methods to stimulate spermatogenesis and to enhance milt production, maintaining a good sperm quality, would be beneficial to aquaculture.

It is now well established that stimulation of milt production in adult teleosts can be achieved by treatment with either gonadotropins $(\mathrm{GtH})$ or gonadotropin releasing hormones and their synthetic agonists (GnRHa) (Zohar and Mylonas, 2001). Among the mammalian gonadotropins, human chorionic gonadotropin (hCG) is effective in inducing spermatogenesis and spermiation in fish (Stacey and Peter, 1979; Donaldson and Hunter, 1983). Human chorionic gonadotropin has been used successfully in goldfish Carassius auratus, rainbow trout 
88

89

90

91

92

93

94

95

96

97

98

99

100

101

102

103

104 105

$\underline{\text { Oncorhynchus mykiss, gilthead bream Sparus aurata, European eel Anguilla }}$ $\underline{\text { anguilla, }}$ and Japanese eel Anguilla japonica (Donaldson and Hunter, 1983; Ohta et al., 1997), New Zealand snapper Pagrus auratus (Pankhurst, 1994) and catfish, Pangasius bocourti (Cacot et al., 2003). No information is available, so far, on the use of hCG to stimulate spermatogenesis and spermiation in European sea bass. Zanuy et al. (1999) showed that sustained administration of testosterone (T) stimulates spermatogenesis in prepubertal European sea bass, and suggested that $\mathrm{T}$ could be involved in the onset of puberty, probably acting via positive feedback on the GnRH system. In adult European sea bass, GnRH treatment of mature males during the reproductive period enhanced sperm production (Sorbera et al., 1996). Since no information is available concerning the effect of hCG treatment on both spermatogenesis and spermiation in one-year old European sea bass, the aims of the present study were (a) to compare sperm quality (motility class and duration, density, fertilizing capacity and endurance to cryopreservation) between precocious and normally maturing males, (b) to examine the potential of hCG to increase spermiation in precocious males and (c) to examine the potential of hCG to induce spermatogenesis and spermiation in non-precocious 1-year-old males. 
105

106

107

108

109

110

111

112

113

114

115

116

117

118

119

120

121

122

123

124

125

126

127

128

\section{Materials and methods}

\subsection{Fish}

The experiments were performed during January at the IFREMER station of Palavas Les Flots (France). One year old European sea bass (mean weight $\pm \mathrm{SD}$, $125 \pm 34 \mathrm{gr}$ ) were taken from a mixed stock (rearing in natural photothermal regime during the preceding year), and were maintained under constant temperature $\left(12 \pm 1^{\circ} \mathrm{C}\right)$ and light $(8 \mathrm{~L} / 16 \mathrm{D})$ for the entire duration of the experiment. Fish were anesthetised in 2-phenoxyethanol (120 ppm) (Sehdev et al., 1963) and checked for the presence of running milt by application of gentle abdominal pressure. Males were classified as spermiating (precocious fish) if milt could be expressed. One hundred precocious and 100 non-precocious fish were selected. Fish were distributed in four identical fibreglass tanks (50 per tank).

Each tank was lightproof, circular (2 m diameter) and was provided with wellaerated running seawater (35\%). Fish were fed daily to satiation with a commercially available dry diet (47\% protein and $18 \%$ fat). Prior to the start the trial, fish were individually weighed and marked by tags (Fish eagle PIT tags, USA) placed in the dorsal musculature. Sperm stripped from reared adult European sea bass (2 years old, length $32-38 \mathrm{~cm}$, weight $450-550 \mathrm{~g}$, and maintained under natural temperature) was used as control for quality assessment of sperm obtained from precocious fish. The evaluation of the sperm quality was performed at the beginning of the trial after the selection of the groups.

\subsection{Experimental protocol and sampling}

Experiment 1: effect of hCG treatment on precocious fish. 
Fish were divided into an experimental and a control group (see above) as follows: 50 spermiating fish, were injected weekly for three weeks with $1000 \mathrm{IU}$ hCG $\mathrm{Kg}^{-1} \mathrm{BW}$ (precocious hCG-treated). As control, 50 spermiating fish were injected weekly for three weeks with physiological saline (precocious salinetreated). Before each handling, the fish were anaesthetised with phenoxy-2 ethanol. All fish of each group were stripped weekly. Milt volume was assessed on all fish while sperm quality was assessed only on ten fish per group. The gonadosomatic index (GSI) and the testis histology were determined at the end of the trial ( 3 weeks) on ten spermiating fish randomly taken per group. The gonadosomatic index $(\mathrm{GSI})$ was estimated as follows: $\mathrm{GSI}=\left(\mathrm{G}_{\mathrm{W}} / \mathrm{B}_{\mathrm{W}}\right) * 100$, where $G_{W}$ is the gonad weight and $B_{W}$ is the body weight of each animal.

Experiment 2: effect of hCG treatment on non-precocious fish.

Fish were divided into an experimental and a control group as follows: 50 non-precocious fish were injected weekly for three weeks with $1000 \mathrm{IU}$ hCG $\mathrm{Kg}^{-1}$ BW (non precocious hCG-treated). As control, 50 non-precocious fish were injected weekly for three weeks with physiological saline (non precocious salinetreated). Before each handling, the fish were anaesthetised with phenoxy-2 ethanol. All fish of each group were stripped weekly to evaluate the number of spermiating males. Fish that resulted non-spermiating, either before and/or after hCG- and saline treatment were classified as immature. Within the spermiating males after one week of hCG treatment, ten were stripped weekly to assess sperm quantity and quality. Sperm stripped from precocious saline-treated European sea bass was used, as control for quality assessment of spermiating non-precocious fish after hCG-treatment. In order to evaluate the stages of gonadal development, 
154 GSI and testis histology were determined weekly by collecting gonads from fish

155 that did not spermiate (immature) after the hCG treatment, and from fish non-

156 spermiating (immature) belonging to saline-treated group $(\mathrm{n}=8-10)$. In addition,

157 the GSI and the gonadal histology were also determined at the end of the trial in

158 spermiating non-precocious fish after hCG-treatment, in spermiating non-

159 precocious fish after saline-treatment and in non spermiating, non precocious

160 saline-treated group $(\mathrm{n}=5-10)$.

161

162

\subsection{Gonadal development and testes histology}

163 Testes were quickly removed, weight to the nearest $0.001 \mathrm{~g}$ and fixed in

164 Bouin's fixative. Serial $6 \mu \mathrm{m}$-thick parafin sections were stained with

165 haematoxylin and eosin. Testicular development was classified using the

166 maturation stages of Zanuy et al. (1999). Briefly: undifferentiated gonads (Stage I)

167 contained only isolated germinal cells and somatic elements; early differentiated

168 testis (Stage II) were organized in seminiferous lobules and differentiated

169 spermatogonia; immature differentiated testes (Stage III) contained cysts of

170 spermatogonia distributed to the periphery and a wide lobular lumen; early

171 maturing testis (Stage IV) had an increased lobular size and cysts containing

172 spermatocytes; maturing testis (Stage V) had cysts containing cells in all stages of

173 development (spermatogonia, spermatocytes and spermatids) and same

174 spermatozoa were released into the lumen; Spermiating fish (Stage VI) had

175 lobules filled with sperm that was released into the seminiferous duct.

176

177

\subsection{Gamete collection}


For sperm collection, a gentle abdominal pressure was applied and a drop of milt was collected from the dry-blotted gonopore area into a $2 \mathrm{ml}$ syringe. Urine and potentially urine-contaminated semen were discarded carefully. The semen was maintained at $4^{\circ} \mathrm{C}$ until used.

Females were induced to spawn by a single injection of $10 \mu \mathrm{gg}^{-1}$ of [D$\left.\operatorname{Trp}^{6}\right]$-gonadotropin-releasing hormone-agonist ([D-Trp $\left.\left.{ }^{6}\right]-G n R H a\right)$ and were allowed to ovulate in individual tanks $\left(1 \mathrm{~m}^{3}\right)$ maintained at $13^{\circ} \mathrm{C}$, about $72 \mathrm{~h}$ after injection. For each fertilization trial, eggs from one female were collected by stripping and were assessed for viability by their morphological features (perfect rotundity, development of a perivitelline space, yolk translucency) under a dissecting microscope, according to Fauvel et al., (1992).

\subsection{Assessment of sperm characteristics, cryopreservation and insemination}

Sperm concentration, percentage of spermatozoa showing forward motility, and fertilising ability were determined. In addition, the effect of cryopreservation on sperm quality was examined.

Sperm concentration was determined according to Fauvel et al. (1999) by spectrophotometry (Beckman DU600) at $260-\mathrm{nm}$, using the equation $\mathrm{SC}=(0.806$ OD-0.032) $10^{8}$, where SC and OD are sperm concentration (spermatoza $\mathrm{mL}^{-1}$ ) and optical density, respectively. To assess sperm motility, sperm samples were diluted initially to $1: 150(\mathrm{v}: \mathrm{v})$ in an isotonic non-activating medium (NAM) containing (in mg ml${ }^{-1}$ ) $3.5 \mathrm{NaCl} ; 0.11 \mathrm{KCl} ; 21.23 \mathrm{MgCl} ; 0.39 \mathrm{CaCl} 2 ; 1.68$ NaHCO3; 0.08 Glucose; $10 \mathrm{BSA}$; $\mathrm{pH}=7.7$ and the absence of motility was checked. Then, aliquots of $6 \mu \mathrm{l}$ were immediately mixed with $60 \mu 1$ seawater. The samples were observed for the first time 10 seconds after activation, under the 
203

204

205

206

207

microscope (x40 magnification) connected to a camera and a video monitor. The percentage of motile cells was evaluated simultaneously by two observers in three replicates per sample using the mean for statistical analyses. Motility was categorized (motility class) according to Suquet et al. (1992a) as 0 for immotile sperm, 1 for $0-20 \%$ motile cells, 2 for $20-40 \%, 3$ for $40-60 \%, 4$ for $60-80 \%$ and 5 for $80-100 \%$. The duration of motility was defined as the period of time between activation and cessation of any forward movement.

The cryopreservation protocol was applied to sperm collected from adult and precocious European sea bass. Immediately after collection, fresh sperm was diluted 1:3 in freezing diluent. The freezing diluent used was Mounib's medium complemented with $10 \%$ dimethyl sulfoxyde and $10 \mathrm{mg} \mathrm{mL}^{-1}$ bovine serum albumin (Dreanno et al., 1997). The dilution was not allowed to equilibrate and was immediately placed in straws (50 $\mu 1$ fresh sperm per straw) and then directly subjected to the freezing protocol. Straws were placed for $15 \mathrm{~min}$ on a tray in nitrogen vapour, $6.5 \mathrm{~cm}$ above liquid nitrogen surface. Straws were thawed in a waterbath at $35^{\circ} \mathrm{C}$ for $5 \mathrm{~s}$ (Fauvel et al., 1998). Fertilising ability of fresh and cryopreserved sperm was compared using the following experimental protocol. Before freezing, sperm was diluted 1:3 (v/v) in Mounib's medium and fresh sperm were prepared by direct dilution 1:3 (v/v) in NAM in order to keep similar insemination conditions. Aliquots of egg from the same batch $(5 \mathrm{ml}$, containing about 5000 eggs) were placed in 10-ml beackers and inseminated with $150 \mu$ of diluted sperm to obtain $\sim 50010^{3}$ spermatozoa per egg as previously suggested (Fauvel et al., 1999). Frozen sperm samples were thawed just before insemination in order to avoid a possible decrease of fertility due to post-thaw delay. Sperm samples were mixed with the eggs using gentle agitation. Fertilisation was 
228 triggered by adding $2.5 \mathrm{ml}$ of seawater $\left(38 \mathrm{psu} ; 13^{\circ} \mathrm{C}\right)$. Inseminated eggs were

229 then transferred into $100-\mathrm{ml}$ container with sea water. After $3 \mathrm{~h}$ at $13^{\circ} \mathrm{C}$, the

230 fertilisation success was assessed under a dissecting microscope, by examing 100

231 randomly chosen eggs. Eggs were assumed to be fertilised when they contained an

232 embryo at the four-cell stage or greater.

233

234 2.6. Statistical analysis

235 The statistical analyses were performed using the SYSTAT statistical analysis 236 package (SYSTAT, 1991). The means of continuous variables such as sperm 237 volume and concentration, motility duration, GSI and fertilization success after 238 angular transformation (when required) were compared by means of one-way or 239 two-way analysis of variance (ANOVA) followed by a Tukey test of pairwise 240 multiple comparisons. The comparison of motilities determined as discrete 241 variables (classes) were achieved using a Friedmann repeated-measures ANOVA 242 on ranks. Percentage of spermiation and frequency distribution of testicular 243 classes were analyzed, after arcsin transformation, using a Chi-squared test. In all 244 cases, differences were accepted at $\mathrm{P}<0.05$. Data are expressed as means \pm S.E.M. 


\section{Results}

\subsection{Characterization of precocious European sea bass sperm}

Fresh sperm produced by precocious fish had mean value of motility class,

mean maximum motility duration, sperm concentration and fertilization ability

similar (Two-way ANOVA; P > 0.05) to that produced by adult 2-year-old fish

(Fig. 1). The motility duration of sperm collected both by adult and precocious

251 fish was significant (Two-way ANOVA; $\mathrm{P}<0.05$ ) reduced by cryopreservation process (Fig. 1).

\subsection{Effect of hCG treatment on spermiation of precocious European sea bass}

Treatment with hCG after one or two weekly injections induced a significant increase of milt volume (One-way ANOVA; Tukey's HSD, $\mathrm{P}<0.05$ ), with respect to the controls. No difference between hCG-treated and control (saline treated) was observed after the third injection (Fig. 2A).

No significant differences were observed between precocious hCG-treated and precocious saline-treated in terms of sperm concentration, motility duration (One-way ANOVA; P>0.05) and class (Friedmann repeated-measures ANOVA on ranks; $\mathrm{P}>0.05$ ) (Table 1). Sperm concentration ranged between 45 and $66 \times 10^{9}$

263 spermatozoa $\mathrm{ml}^{-1}$ in the precocious hCG-treated group and from 45 to $60 \times 10^{9}$ 264 spermatozoa $\mathrm{ml}^{-1}$ in the precocious saline-treated group. The motility class ranged 265 between 4 and 5 , and the motility duration was greater than $50 \mathrm{sec}$.

266 No significant differences (Two-way ANOVA; P > 0.05) were observed in terms 267 of GSI between precocious hCG-treated and precocious saline-treated groups 268 (Fig. 3). The GSI values of both precocious hCG-treated and precocious saline- 
treated are significant (Two-way ANOVA; $\mathrm{P}<0.05)$ different from those of immature fish.

\subsection{Effect of hCG treatment on non-precocious European sea bass}

A higher percentage (Chi-squared test; $\mathrm{P}<0.05)$ of spermiating fish was observed in the non-precocious hCG treated group compared to non-precocious saline group, starting from the first week of hormone application (Table 1). At the end of the trial, 29 out of 50 of the hCG-treated fish were spermiating and among these 23 produced a large amount ( $>200 \mu 1$ per fish) of milt sufficient to perform the sperm quality analyses. On the contrary, at the end of the trial 5 out of 50 fish of the non precocious saline-treated group were spermiating and only one of these produced a large volume of milt.

The spermiating fish of non precocious hCG -treated group produced milt continuously up to the $3^{\text {rd }}$ week of the experiment although the volume declined gradually (Fig. 2B). No differences were observed in terms of sperm concentration, motility class, motility duration and fertilizing ability due to the hormonal treatment (Table 1). Sperm concentration ranged between 46 and 60 $\mathrm{x} 10^{9}$ spermatozoa $\mathrm{ml}^{-1}$ in both groups. The motility class ranged between 4 and 5 , and the motility duration was longer than $50 \mathrm{sec}$.

No significant differences (Two-way ANOVA; P > 0.05) were observed in terms of GSI between spermiating, non-precocious hCG-treated and spermiating, non precocious saline-treated fish (Fig. 3). These GSI values resulted significant (Two-way ANOVA; $\mathrm{P}<0.05$ ) different from that determined in immature fish (not spermiating, non precocious saline-treated fish). In addition, the GSI determined weekly in fish that were immature (belonging to 
294 non precocious hCG-treated group) was similar (Two-way ANOVA; P>0.05)

295 to the GSI of immature animals of control group (non precocious saline-treated 296 group).

297 All non-spermiating fish had fully differentiated testes in which the 298 spermatocysts contained germ cells at various stages of development (stage II, 299 III, IV and V). The histological examination (data not shown) indicated that, the 300 testes of immature fish, belonging to non precocious saline-treated group had a 301 higher frequency of stages II (30\%) and III (35\%) with a small percentage of 302 stage IV (18\%) and stage V (20\%). On the contrary, hCG treatment induced a 303 significant (Chi-squared test; $\mathrm{P}<0.05)$ increase of testicular development $(46 \%$ 304 stage III, 42\% stage IV and 40\% stage V) (Fig.4A). In addition, the gonads of 305 spermiating, non-precocious fish after hCG treatment (Fig. 4B) were in similar 306 stage of development compared to the gonad of precocious hCG-treated fish $307 \quad$ (Fig . 4C). 


\section{Discussion}

310 The present study demonstrates for the first time the ability of hCG to increase

311 spermiation in precocious European sea bass and enhance spermatogenesis and

312 spermiation in non-precocious one-year-old fish.

313 Fish breeders may benefit from using early maturing broodstock since the

314 generation interval would be reduced, allowing more frequent selection. In order

315 to be used for reproduction, the quality of the sperm produced by precocious

316 animals must be similar to that of adults and its quantity must be adequate. Our

317 data demonstrate that precocious European sea bass are reproductively functional,

318 since the quality of their sperm is similar to that of adults in terms of

319 concentration, motility class, motility duration and fertilizing capacity. In addition,

320 the sperm's ability to endure cryopreservation was also similar in precocious and

321 adult fish. Futhermore, milt volume produced by precocious European sea bass

322 (about $1,6 \mathrm{ml} / \mathrm{Kg}$ body weight) is similar to that produced by adult fish (Sorbera

323 et al., 1996). Previous studies carried out on stripped bass (Morone saxatilis) and

324 rainbow trout have demonstrated that sperm stripped from precocious and adult

325 fish posses similar motility and relative volume of milt produced but different

326 concentration, though no information is available on their fertilizing ability

327 (Holland et al., 1996; Liley et al., 2002).

328 In the present paper it was also demonstrated that the volume of milt produced

329 by precocious animals can be increased by hCG treatment, without affecting

330 gamete quality. In a variety of adult freshwater and seawater teleosts, it has been

331 demonstrated that hCG both stimulates advancement of spermiation (Crim et al.,

332 1983; Sorenson and Pankhurts, 1988) and promotes an increase in milt volume 
333 (Takashima et al., 1984; Kreiberg et al., 1987; Yeuh et al., 1990). Our results

334 suggest that hCG has similar effects in precocious European sea bass. The

335 conclusion is also supported by the observation that a single injection of hCG in

336 precocious European sea bass produced a significant increase of milt volume,

337 similar to the situation in adult catfish (Cacot et al., 2003) and adult

338 Rhynchocypris oxicephalus (Park et al., 2002). In many teleost fishes, plasma

339 luteinizing hormone (LH) levels increase just prior to production of the

340 expressible milt (Swanson, 1991) and remain stable during the spermiation period

341 (Breton et al., 1988). Human chorionic gonadotropin is an LH-like hormone that

342 mimics LH and, due to its relatively long retention time in circulation (Ohta and

343 Tanaka, 1997), it stimulates the spermiation process by acting on gonadal

344 maturation (Miura et al., 1991a). The increase of expressible milt observed after

345 the hCG treatment in the present study is in agreement with the established role of

346 LH in regulating the process of spermiation (Swanson, 1991; Nagahama, 1994). In

347 adult European sea bass, the relationship between continuous stimulation of LH

348 release and the corresponding enhancement of milt production has been

349 demonstrated (Mañanòs et al., 2002).

350 Hormonal treatment induced high percentage of spermiating fish with a high

351 milt volume produced. The sperm stripped from these fish showed similar

352 qualitative characteristics (concentration, motility percentage and duration, and

353 fertilisation capacity) to that of both precocious and adult fish. The increase of

354 spermiation percentage due to the first injection of hCG, could be explained by the

355 capacity of hCG (LH-like hormone) to induce the emptying of spermatocysts that

356 are in an advanced stage of spermatogenesis. LH stimulates sperm hydration,

357 migration and release (Schulz and Miura, 2002). 
The histology of the testis of non-precocious fish spermiating after hCG treatment showed similar characteristics to those of precocious treated fish.

360 Furthermore, in fish which did not become spermiating after treatment, we observed a high degree of incidence of stages IV and V of testicular development. These results suggest an involvement of the hCG (LH-like) hormone in the induction of spermatogenesis and are in agreement with the results reported for

364 adult European sea bass (Rodrìguez et al., 2000; Mañanos et al., 2002) and other species (Weil and Crim, 1983; Pankhurst et al., 1986; Pankhurst, 1994). completion of spermatogenesis and initiation of spermiation. Our results are consistent with those reported for Japanese and European eel, in which both a single administration or weekly injections of hCG induced spermatogenesis (Khan et al., 1987; Miura et al., 1991a; Ohta et al., 1996a; Ohta and Tanaka, 1997; Perez et al., 2000). The failure of the hCG treatment to produce spermiation in some non-precocious European sea bass could be explained at least partially, by the

373 individual variability of gonadal development observed at the time of the first

374 injection. Human chorionic gonadotropin administration to fish at advanced stages of development could induce spermiation, while when administered to fish at early

376 developmental stages, could only stimulate advancement in gonadal maturity but

377 not spermiation. Other possible reasons could be differences in plasma hCG

378 concentration (after the injection) or differences in the androgen production in

379 response to the hormonal stimulation, as also reported for Japanese eel (Ohta and

380 Tanaka, 1997). The observation that the GSI was similar in animals which were

381 spermiating naturally and in hCG-treated animals suggests that hCG stimulate

382 spermatogenesis and spermiation in a physiological manner. 
383 Artificial induction of testicular maturation by hormonal treatment could affect

384 the quantity and the quality of milt produced (Zohar and Mylonas, 2001). For

385 example in Japanese eel hCG treatment led to a production of a small sperm

386 volume (Ohta et al., 1997), while injections of pituitary extracts in adult carp

387 Cyprinus carpio and rainbow trout decreased sperm concentration, by increasing

388 seminal fluid production but not spermatozoa production (Clemens and Grant,

389 1965). However, more recently, it has been demonstrated that a decrease of sperm

390 concentration does not occur in European sea bass and white bass Morone

391 chrysops (Sorbera et al., 1996; Mylonas et al., 1997). In precocious and non-

392 precocious European sea bass, our results also demonstrated that hormonal

393 treatment with hCG produced an increase of milt volume production without

394 affecting concentration or quality.

395 Milt production in some fishes is affected by stripping frequency. For

396 example, in turbot Scophthalmus maximus and European sea bass during the first

397 reproductive season, an increase in stripping decreased the period of spermiation

398 (Suquet et al., 1992b; Fauvel et al., 1999). Similar to these findings, we observed

399 that in precocious and spermiating non-precocious hCG-treated European sea

400 bass, the milt volume stripped decreased during the trial. In adult European sea

401 bass at the end of the reproductive period, GnRHa implants also failed to prevent

402 decrease due to successive stripping (Rainis et al., 2003), while both in GnRH-

403 treated and control fish, the frequency of stripping had no deleterious effect on

404 length of the spermation period (Sorbera et al., 1996). Therefore, our results

405 suggest that the effect of stripping on sperm production in precocious European

406 sea bass was similar to that of fish that are in the first reproductive cycle. 
407 In conclusion, it was demonstrated that precocious European sea bass are 408 reproductively functional, since the quality of their sperm is similar to that of 409 adults in terms of concentration, motility class, motility duration and fertilizing 410 capacity. Our results demonstrate that hCG treatment could be used to increase the 411 sperm produced by precocious 1-year-old European sea bass males without 412 altering sperm quality, and that hCG treatment also enhanced spermatogenesis and 413 spermiation in non-precocious fish.

414

415 


\section{Acknowledgements}

416 The authors wish to thank Mrs. Nicolette S. James for her language assistance.

417 


\section{References}

418 Asturiano, J.F,, Sorbera, L.A., Ramos, J., Kime, D.E., Carrillo, M., Zanuy, S., 2000.

419 Hormonal regulation of the European sea bass reproductive cycle: and individualised

420 female approach. J. Fish Biol. 56, 1155-1172.

421 Breton, B., Sambroni, E., Gillet, C., 1988. Gonadotropin releasing hormone (GnRH)

422 and gonadotropin $(\mathrm{GtH})$ variation around the spawning period in a wild population of

423 roach (utilus rutilus) from Leman lake. I The male. Aquat. Living Resour.. 1, 93-

42499.

425 Bye, V.J., Lincoln, R.F., 1986. Commercial methods for the control of sexual

426 maturation in raimbow trout (Salmo gairdneri R.) Aquaculture 57, 299-309.

427 Cacot, P., Eeckhoutte, P., Muon, D.T., Trieu, N.V., Legendre, M., Mariojouls, C.,

428 Lazard, J., 2003. Induced spermiation and milt management in Pangasius bocourti

429 (Sauvage, 1880). Aquaculture 215, 67-77.

430 Carrillo, M., Zanuy, S., Prat, F., Serrano, R., Bromate, N., 1993. Environmental and

431 hormonal control of reproduction in sea bass. In: Muir, J..F., Roberts, R.J., (Eds.),

432 Recent Advances in Aquaculture. Blackwell, Oxford, pp. 43-54.

433 Carrillo, M., Zanuy, S., Prat, F., Cerdá, J., Ramos, J., Mañanós, E., Bromage, N.,

434 1995. Sea bass (Dicentrarchus labrax), In: Bromage, N., Roberts, R.J. (Eds.),

435 Broodstock Management and Eggs and Larval Quality. Blackwell, Oxford, pp. 138436168.

437 Clemens, H.P., Grant, F.B., 1965. The seminal thinning response in carp

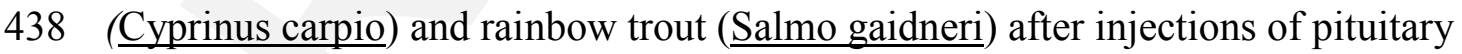

439 extracts. Copeia 174-177.

440 Crim, L.W., Evans, D.M., Vickery, B.H., 1983. Manipulation of the seasonal

441 reproductive cycle of the landlocked atlantic salmon (Salmo salar) by LHRH 
442 analogues administered at various stages of gonadal development. Can. J. Fish

443 Aquat. Sci. 40, 61-67.

444 Donaldson, E.M., Hunter, G.A., 1983. Induced final maturation, ovulation, and

445 spermiation in cultured fish. In: Hoar, W.S., D.J., Randall, E.M. Donaldson, (Eds.),

446 Fish Physiology. Academic Press, New York, USA, pp. 351-403.

447 Dreanno, C., Suquet, M., Quemener, L., Cosson, J., Firville, E., Normant, Y.,

448 Billard, R., 1997. Cryopreservation of turbot ( Scophthlmus maximus) spermatozoa.

449 Theriogenology, 48, 589-603.

450 Fauvel C., Omnes M.H., Suquet M., Normant Y., 1992. Reliable assessment of

451 overripening in turbot (Scophthalmus maximus) by a simple $\mathrm{pH}$ measurement.

452 Aquaculture 117, 107-113.

453 Fauvel, C., Suquet, M,. Dreanno, C., Zonno, V., Menu, B., 1998.

454 Cryopreservation of seabass (Dicentrarchus labrax) spermatozoa in experimental

455 and production simulating conditions. Aquat. Living Resour. 11 (6), 387-394.

456 Fauvel, C., Savoye, O., Dreanno, C., Cosson, J., Suquet, M., 1999. Characteristics of

457 sperm of captive sea bass in relation to its fertilization potential. J. Fish Biol. 54,

$458 \quad 356-369$.

459 Holland, M.C., Mylonas, C.C., Zohar, Y., 1996. Sperm characteristics of

460 precocious 1-year-old male striped bass Morone saxatilis. J. World Aquacult.

461 Soc. 27, 208-212.

462 Khan, I.A., Lopez, E. Leloup- Hatey, J., 1987. Induction of spermatogenesis and

463 spermiation by a single injection of of human chorionic gonadotropin in intact and

464 hypophysectomized immature European eel (․ㅡguilla anguilla). Gen Comp.

465 Endocrinol. 68, 91-103. 
466 Kreiberg, H., Hunter, G.A., Donaldson, E.M., Clarke, W.G., Baker, I., 1987. Induced 467 ovulation and spermiation in the Pacific herring (Clupea harengus pallasi) using

468 salmon pituitary preparations and a synthetic gonadotropin-releasing hormone 469 analogue. Aquaculture 61, 155-661.

470 Liley, N.R., Tamkee, P., Tsai, R., Hoysak, D.J., 2002. Fertilization dynamics in 471 rainbow trout (Oncorhynchus mykiss): effect of male age, social experience, and 472 sperm concentration and motility on in vitro fertilization. Can. J. Fish Aquat. Sci. 59, 473 144-152.

474 Mañanòs, E., Carrillo, M., Sorbera, L.A., Mylonas, C.C., Asturiano, J.F., Bayarri, 475 M.J., Zohar, Y., Zanuy, S., 2002. Luteinizing hormone and sexual steroid plasma 476 levels after treatment of European sea bass whit sustained-release delivery systems 477 for gonadotropin-releasing hormone analogue. J. Fish Biol. 60, 328-339.

478 Miura, T., Yamauchi, K., Nagahama, Y., Takahashi, H., 1991a. Induction of 479 spermatogenesis in male Japanese eel, Anguilla japonica, by a single injection of 480 human chorionic gonadotropin. Zool. Sci. 8, 63-73.

481 Mylonas, C.C.; Gissis, A.; Magnus, Y., Zohar, Y., 1997. Hormonal changes in male 482 white bass (Morone chrysops) and evaluation of milt quality after treatment with a 483 sustained-release GnRHa delivery system. Aquaculture 153, 301-313.

484 Nagahama, Y., 1994. Endocrine regulation of gametogenesis in fish. Int. J. Dev. 485 Biol. 38, 217-229.

486 Ohta, H., Kagawa, H., Tanaka, H., Okuzawa, K., Hirose, K., 1996a. Milt production 487 in the Japanese eel Anguilla japonica induced by repeated injections of human 488 chorionic gonadotropin. Fish. Sci. 62, 44-49.

489 Ohta, H., Tanaka, H., 1997. Relathionship between serum levels of human 490 chorionic gonadotropin (hCG) and 11-ketotestosterone after a sigle injection of 
$491 \mathrm{hCG}$ and induced maturity in the male Japanase eel, Anguilla japonica.

492 Aquaculture 153, 123-134.

493 Ohta, H., Kagawa, H., Tanaka, H., Okuzawa, K., Hirose, K., 1997. Artificial

494 induction of maturation and fertilization in the Japanese eel, Anguilla japonica.

495 Fish Physiol. Biochem. 17, 163-169.

496 Pankhurst, N.W., 1994. Effects of gonadotropin releasing hormone analogue, human 497 chorionic gonadotropin and gonadal steroids on milt volume in the New Zealand 498 snapper Pagrus auratus (Sparidae). Aquaculture 125, 185-197.

499 Pankhurst N.W., Stacey N.E., Van Der Kraak G., 1986. Reproductive development

500 and plasma levels of reproductive hormones of goldeye, Hiodon alosoides

501 (Rafinesque), taken from the North Saskatchewan river during the openwater season.

502 Can. J. Zool. 64, 2843-2849.

503 Park, I.S., Choi, C.G., Nam, Y.K., Kim, D.S., 2002. The effect of exogenous

504 hormone treatment on spermiation Rhynchocypris oxicephalus (Sauvage and

505 Dabry). J. World Aquacult. Soc. 33, 494-500.

506 Perez, L., Asturiano, J.F., Tomas, A., Zegrari, S., Barrera, R., Espinos, F.J.,

507 Navarro, J.C., Jover, M., 2000. Induction of maturation and spermiation in the

508 male european eel: assessment of sperm quality troughout treatment. J. Fish Biol.

509 57(6), 1488-1504.

510 Pickett, G.D., Pawson, M.G., 1994. Sea bass (Biology, Exploitation and

511 Conservation). Chapman and Hall, London (Fish and Fisheries Series, 12) pp. 337

512 Rainis, S., Mylonas, C.C., Kyriakou, Y., Divanach, P., 2003. Enhancement of

513 spermiation in European sea bass (Dicentrarchus labrax) at the end of the

514 reproductive season using GnRHa implants. Aquaculture 219, 873-890.

515 Rodrìguez, L., Carrillo, M., Sorbera, L.A., Soubrier, M.A., Mañanòs, E., Holland, 
516 M.C.H., Zohar, Y., Zanuy S., 2000. Pituitary levels of three forms of GnRH in the

517 European male sea bass Dicentrarchus labrax L. during sex differentiation and first

518 spawning season. Gen. Comp. Endocrinol. 120, 67-74.

519 Schulz, R.W., Miura, T., 2002. Spermatogenesis and its endocrine regulation. Fish

520 Physiol. Biochem. 26, 43-56.

521 Sehdev, H.S., McBride, J.R., Fagerlund, U.H.M., 1963. 2-phenoxyethanol as

522 general anaesthetic for sockeye salmon. J. Fish Res. Bd. Can. 20, 1435-1440.

523 Sorbera, L.A., Mylonas, C.C., Zanuy, S., Carillo, M., Zohar, Y., 1996. Sustained

524 administration of GnRHa increases milt volume without altering sperm counts in sea

525 bass. J. Exp.Zool. 276, 361-368.

526 Sorensen, P.W., Pankhurst, N.W., 1988. Histological changes in the gonad, skin,

527 intestine and olfactory epithelium of artificially matured male American eels,

528 Anguilla rostrata (LeSueur). J. Fish Biol. 32, 297-307.

529 Stacey, N.E., Peter, R.E., 1979. Central action of prostaglandins in spawning

530 behavior of female gold fish. Physiol. Behav. 22, 1191-1196.

531 Sumpter, J.P., Scott, A.P., 1989. Seasonal variations in plasma and pituitary levels of

532 gonadotrophin in males and females of two strains of rainbow trout ( $\underline{\text { Salmo }}$

533 gairdneri). Gen. Comp. Endocrinol. 75, 376-388.

534 Suquet, M., Omnes, M.H., Normant, Y., Fauvel, C., 1992a. Assessment of sperm

535 concentration and motility in turbot (Scophthlmus maximus L.). Aquaculture 101,

$536 \quad 177-185$.

537 Suquet, M., Omnes, M.H., Normant, Y., Fauvel, C., 1992b. Influence of

538 photoperiod, frequency of stripping and presence of females on sperm output in

539 turbot (Scophthlmus maximus L.). Aquacult. Fish. Manage. 23, 217-225. 
540 Swanson, P., 1991. Salmon gonadotrophins: reconciling old and new ideas. In: Scott, 541 A.P., Supter, J.P., Kime, D.E., Rolfe, M.S., (Eds.). Riproductive Physiology of Fish.

542 Proceedings of the $4^{\text {th }}$ International Symposium. Fish Symposium, Sheffield, pp. 2-7.

543 Takashima, F., Weil, C., Billard, R., Crim, L.W., Fostier, A., 1984. Stimulation of

544 spermiation in carp by LH-RH analogue. Bull Jpn. Soc. Sci. Fish. 50, 1323-1329.

545 Weil, C., Crim, L.W., 1983. Administration of LHRH analogues in various ways:

546 effect on the advancement of spermiation in prespawning landlocked salmon, $\underline{\text { Salmo }}$

547 salar. Aquaculture 35, 103-115.

548 Yeuh, W.S., Lin, S.F., Chang, C.F., 1990. Effects of LHRH-A and hCG on

549 spermiation volume, concentration of milt and sex steroids in black porgy,

550 Acanthopagrus schlegeli. J. Fish. Soc. Taiwan 17, 65-72.

551 Zanuy, S., Carrillo, M., Mateos, J., Trudeau, V., Kah, O., 1999. Effects of sustained

552 administration of testosterone in pre-pubertal sea bass (Dicentrarchus labrax L.).

553 Aquaculture 177, 21-35.

554 Zohar, Y., Mylonas, C.C., 2001. Endocrine manipulations of spawning in cultured

555 fish: from hormones to genes. Aquaculture 197, 99-136. 
557 Table 1

558 The effect of weekly treatment of non-precocious and precocious European sea

559 bass with hCG on percentage of spermiation, sperm motility, density and 560 fertilizing ability in an in vitro insemination trial.

561

\begin{tabular}{|c|c|c|c|c|c|c|}
\hline Weeks & $\mathrm{I}$ & II & III & $\mathrm{I}$ & II & III \\
\hline & \multicolumn{3}{|c|}{$\begin{array}{l}\text { Precocious saline-treated } \\
\qquad \mathrm{n}=10\end{array}$} & \multicolumn{3}{|c|}{$\begin{array}{l}\text { Precocious hCG-treated } \\
n=10\end{array}$} \\
\hline Fertilizing rate $(\%)$ & $65 \pm 5$ & $68 \pm 10$ & $60 \pm 18$ & $66 \pm 2$ & $65 \pm 5$ & $68 \pm 5$ \\
\hline Spermatozoa $\left(\times 10^{9} \mathrm{ml}\right)$ & $55 \pm 5$ & $53 \pm 4$ & $50 \pm 5$ & $58 \pm 8$ & $57 \pm 6$ & $53 \pm 8$ \\
\hline Motility class & 4.5 & 4.3 & 4.2 & 4.6 & 4.6 & 4.2 \\
\hline Motility duration (sec) & $80 \pm 18$ & $70 \pm 15$ & $68 \pm 18$ & $75 \pm 5$ & $83 \pm 5$ & $67 \pm 10$ \\
\hline
\end{tabular}

\begin{tabular}{lcccccc} 
& \multicolumn{3}{c}{ Non precocious saline-treated } & \multicolumn{2}{c}{ Non precocious hCG-treated } \\
\hline Spermiation (\%) & ${ }^{\mathrm{a}} 6 \%$ & ${ }^{\mathrm{a}} 2.7 \%$ & ${ }^{\mathrm{a}} 3.8 \%$ & ${ }^{\mathrm{b}} 44 \%$ & ${ }^{\mathrm{a}} 5 \%$ & ${ }^{\mathrm{b}} 60 \%$ \\
& $(3 / 50)$ & $(1 / 37)$ & $(1 / 26)$ & $(22 / 50)$ & $(1 / 20)$ & $(6 / 10)$
\end{tabular}

\section{Precocious saline-treated Non precocious hCG-treated}

\begin{tabular}{lcccccc} 
& \multicolumn{3}{c}{$\mathrm{n}=10$} & \multicolumn{3}{c}{$\mathrm{n}=10$} \\
\hline Fertilizing rate $(\%)$ & $62 \pm 2$ & $60 \pm 20$ & $65 \pm 18$ & $58 \pm 1$ & $60 \pm 5$ & $68 \pm 5$ \\
Spermatozoa $/ \mathrm{ml} \mathrm{x10} 0^{9}$ & $53 \pm 5$ & $50 \pm 4$ & $52 \pm 7$ & $55 \pm 7$ & $54 \pm 6$ & $58 \pm 8$ \\
Motility class & 4.4 & 4.5 & 4.3 & 4.4 & 4.2 & 4.5 \\
Motility duration (sec) & $78 \pm 20$ & $70 \pm 20$ & $75 \pm 18$ & $68 \pm 5$ & $70 \pm 5$ & $68 \pm 5$
\end{tabular}

562 Values are means \pm SE. Within row, different letters indicates statistically significant

563 differences (Chi-squared test; $\mathrm{P}<0.05)$. The ratios in brackets represent the number of

564 spermiating fish on total. The absolute value of the denominator decrease since: 1) each week

565 fish (8-10) that were not spermiating were used to perform histological studies and 2) it does

566 not include fish which spermiated during the previous week. 
Figure captions

Fig. 1. Mean ( \pm SEM) sperm motility class and duration (upper panel), density and fertilizing ability (lower panel) of precocious and adult European sea bass $(\mathrm{n}=10)$. Asterisks indicate significant differences (Two-way ANOVA; $\mathrm{P}<0.05$ ) between fresh and cryopreserved sperm.

Fig. 2. Mean ( \pm SEM) volume of expressible milt (ml/Kg ${ }^{-1}$ body weight) produced by precocious fish $(\mathrm{A} ; \mathrm{n}=50)$ and non-precocious fish $(\mathrm{B})$ after one, two or three hCG injections. In $\mathrm{B} ; \mathrm{n}=10$ for hCG-treated fish (chosen within those become spermiating after the first treatment), and $n=3$ for saline-treated (all fish become spermiating after the first week). Asterisks indicate significant differences (One-way ANOVA; Tukey's HSD, P<0.05) between saline-treated and hCGtreated fish, at each sample time.

Fig. 3. Mean ( \pm SEM) gonadosomatic index (GSI) determined after three determined after three weekly hCG injection in precocious (Saline-treated and hCG-treated) and in spermiating non-precocious fish after treatment (Salinetreated and hCG-treated) $(n=5-10)$. The GSI was determined at the end of the trial in fish stripped every week. Asterisks indicate significant differences between immature and both precocious and non-precocious fish (Two-way ANOVA; $\mathrm{P}<$ $0.05)$.

Fig. 4. Micrographs of testis belonging to: (A) immature, (B) spermiating nonprecocious hCG-treated fish, and (C) precocious hCG-treated fish sampled at the end of the experiment. (A) Maturing Testis. All stages of germ cell development 
593 are present: Primary spermatogonia (sgA), primary spermatocytes ( $\mathrm{sc1}$,

594 secondary spermatocytes (sc2), spermatids (spt) and spermatozoa (sz). (B, C)

595 spermiating fish . Lumen of the lobules are filled with sperm. Scale bars $=30 \mu \mathrm{m}$. 596 
596

597

598

599

600

601

602

603

604

605

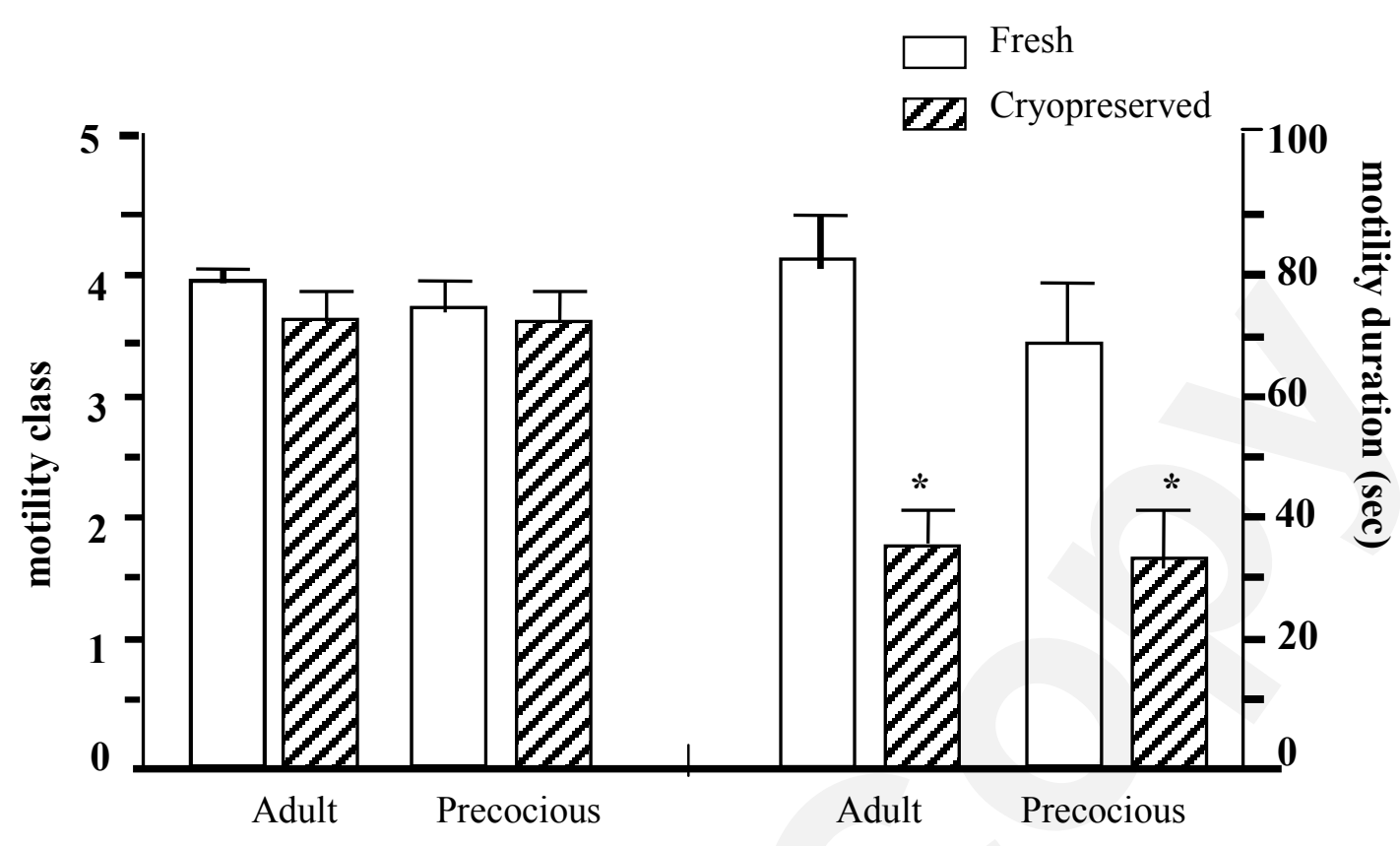

606

607

608

609

610

611

612

613

614

615

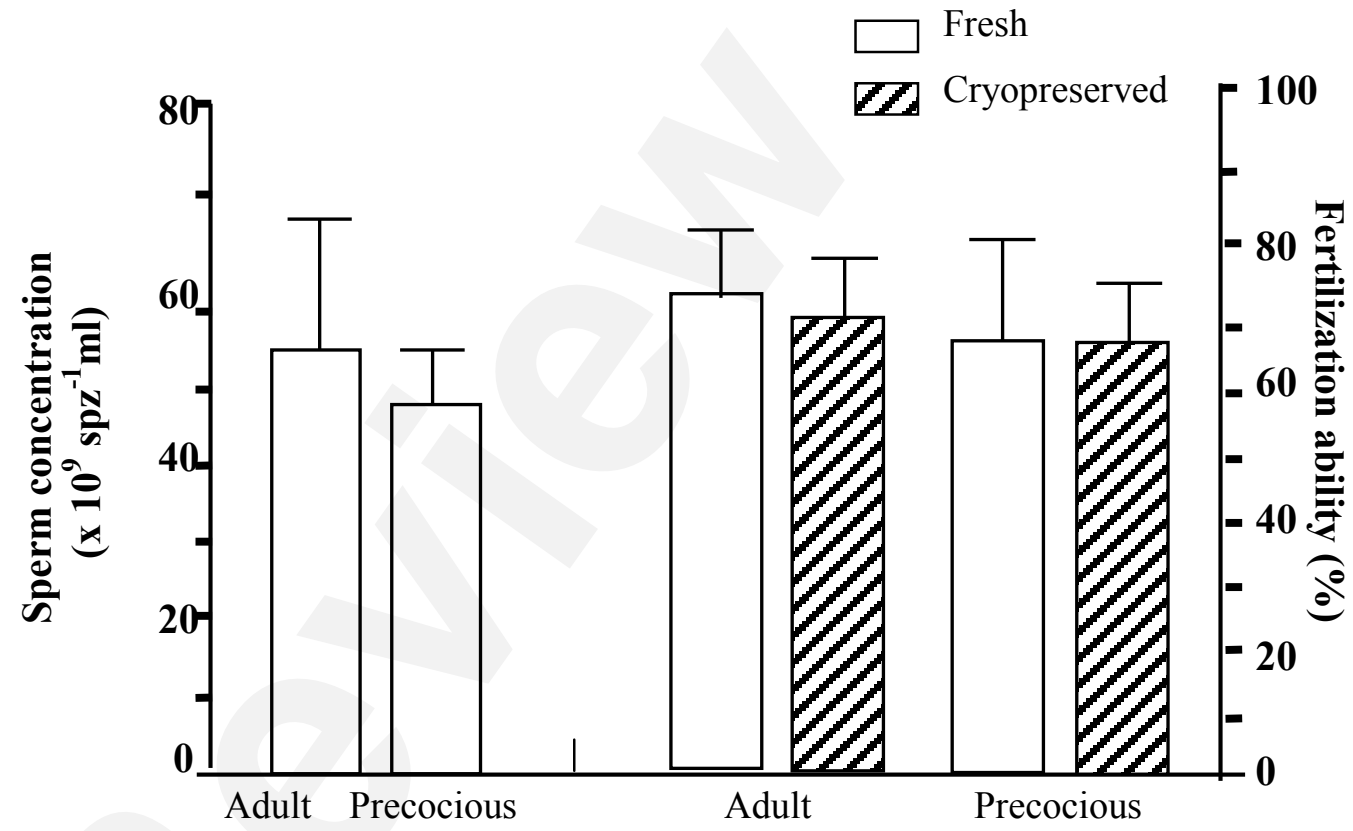

616

617 Fig. 1.

618 
618

619
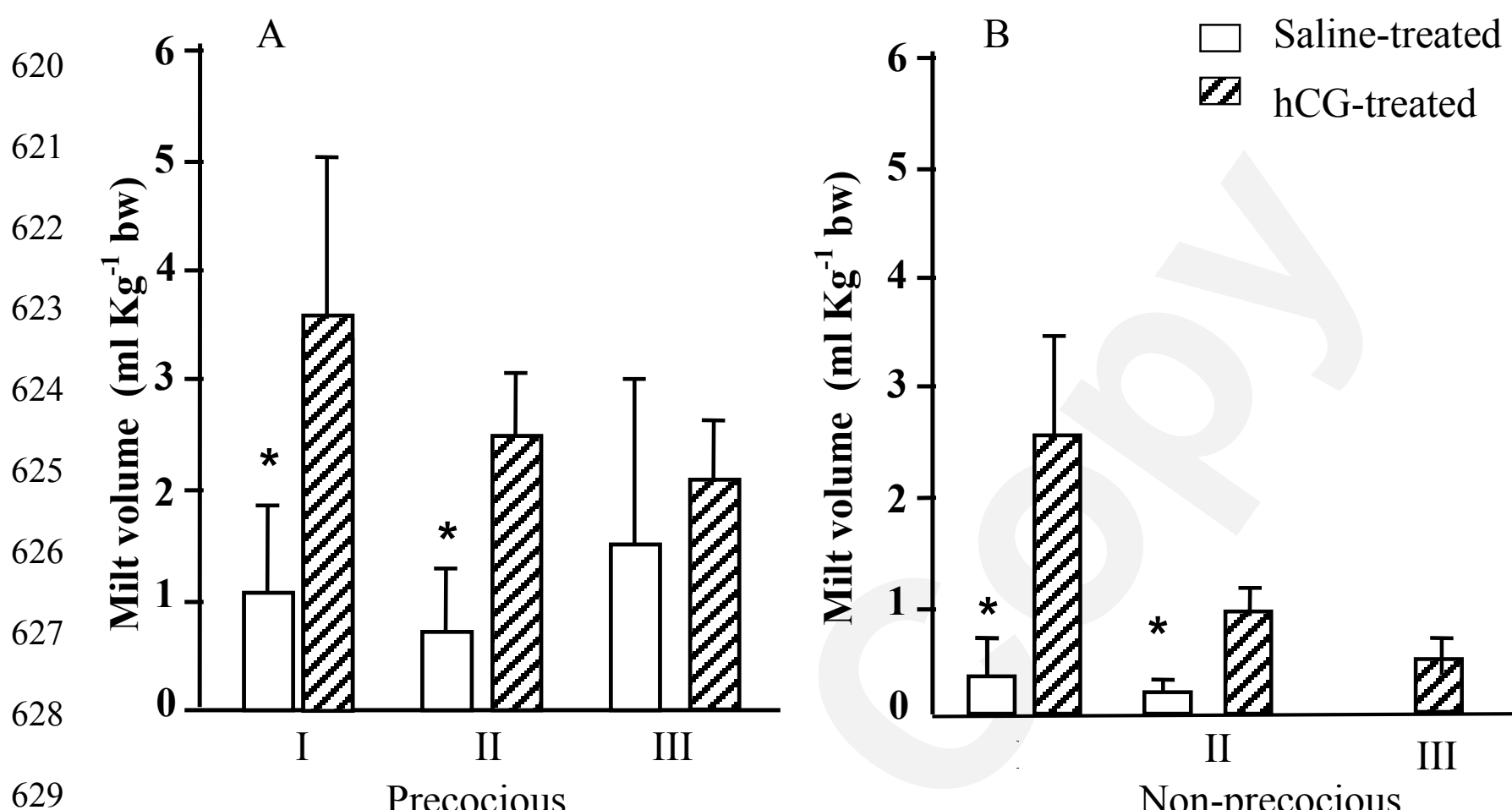

630

Weeks of treatment

631

632 Fig. 2.

633

634

635

636

637

638

639

640

641 
641

642

643

644

645

646

647

648

649

650

651

652 Fig. 3.

653

654

655 $\square$ Saline-treated

$\square$ hCG-treated

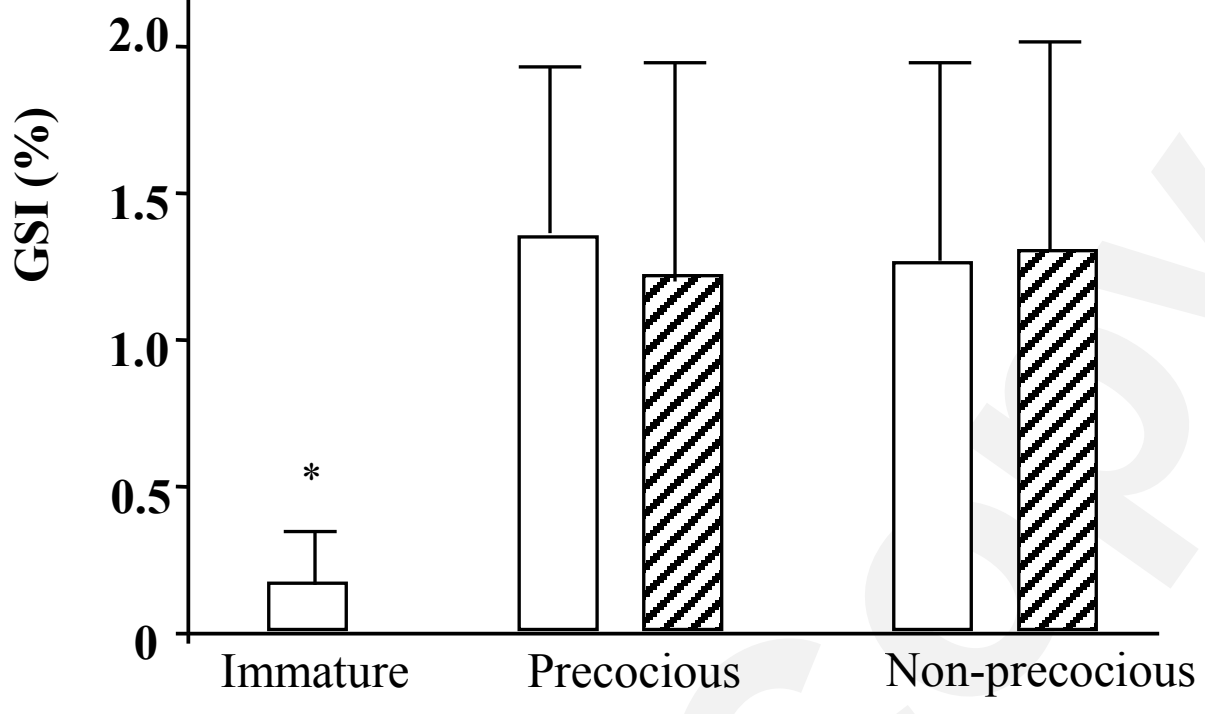



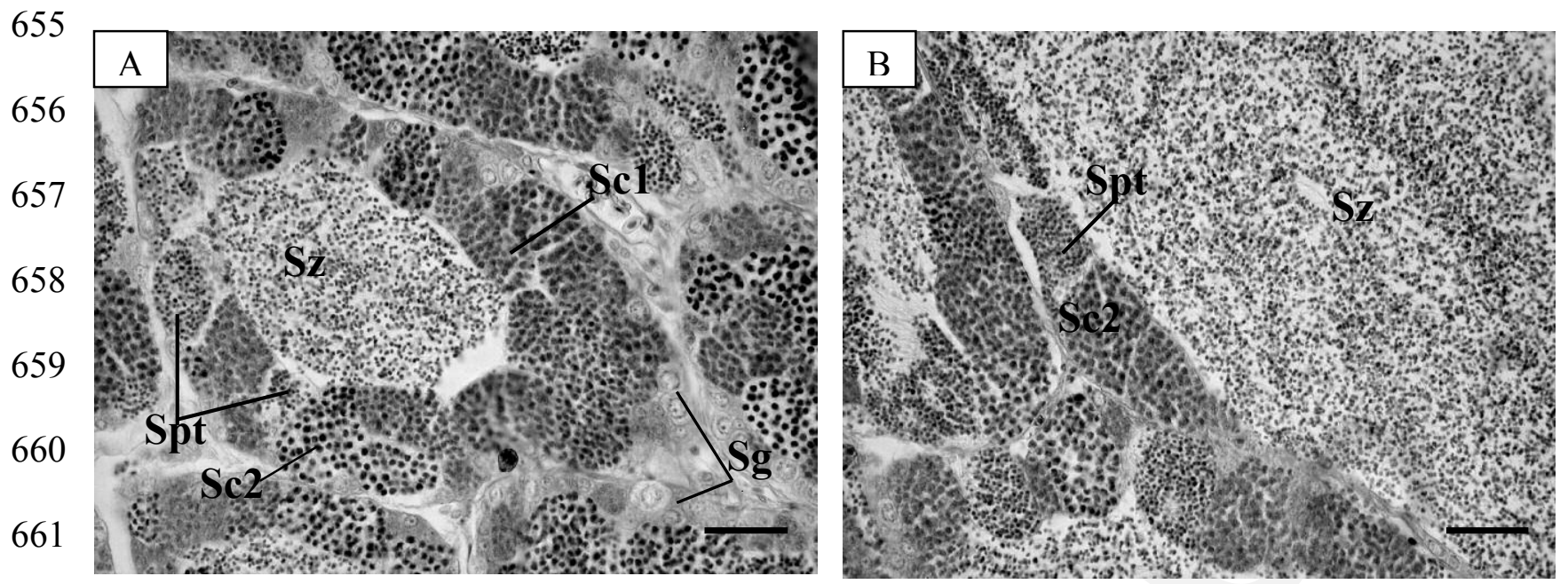

662

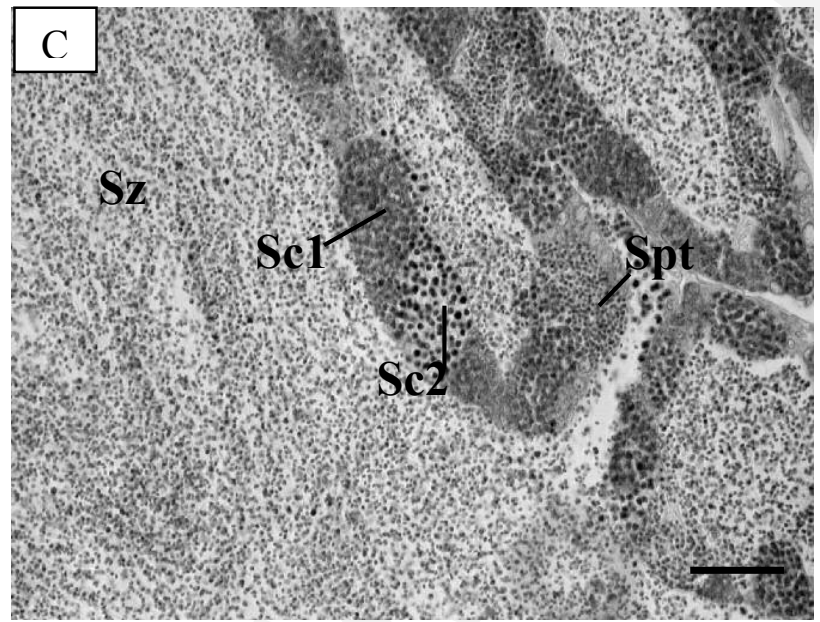

668

669

$670 \quad$ Fig. 4

671 